\title{
A ESCRITA DE SI DE SUJEITOS FEMININOS E SUA DIFERENÇA CULTURAL
}

\author{
Gislene Alves da Silva ${ }^{1}$ \\ Jailma dos Santos Pedreira Moreira ${ }^{2}$
}

\begin{abstract}
Resumo:Trata-se de uma reflexão sobre a escrita de si produzida por mulheres, mais especificamente escrita autobiográfica /memorialista e as tensões que esta tem provocado e ou atravessado. Dessa forma buscamos observar como emergem os escritos autobiográficos de mulheres, sob que condições e que diferenças, que reflexões eles provocam, considerando as marcas de exclusão, a ficção contemporânea, e ainda os dispositivos de controle atuais e a possiblidade de repetição, ou não, destes, por um texto vivo. Para tanto nos basearemos nos estudos de Lacerda (2003), Klinger (2012), Derrida (2001), Richards (2002), Louro (2000) entre outros. Dessa forma, esperamos disseminar o debate, demonstrando a apropriação da escrita pelo feminino, suas marcas diferenciais, ou não, em meio a dinâmica tensional.
\end{abstract}

Palavras-Chave: Escrita memorialística/autobiográfica. Autoria feminina. Diferença cultural.

\section{THE SELF-WRITING OF FEMININE SUBJECT AND HER CULTURAL DIFFERENCE}

\begin{abstract}
This article is reflection about the self-writing that is written by women, more especially the memorialistic / autobiographical writing and the tensions what is provoked and/or crossed. Thus we seek to observe how emerge the autobiographical writings of women, under what conditions and differences that reflections they provoke, considering the tombstones, contemporary fiction, and yet the current control devices and repeating possibility, or not, these for a living text. For both studies will base LACERDA (2003), KLINGER (2012), DERRIDA (2001), RICHARDS (2002) BLOND (2000) among others. Thus, we hope to spread the debate, demonstrating the appropriation of writing by women, their differential marks, or not, in the midst of dynamic tension.
\end{abstract}

Keywords: Memorialistic / autobiographical writing. Female authors. Cultural difference.

\footnotetext{
${ }^{1}$ Mestra em Crítica Cultural, pela Universidade do Estado da Bahia (UNEB/Campus II). Endereço eletrônico: galves11@hotmail.com.

${ }^{2}$ Doutora pela Universidade Federal da Bahia (UFBA), docente do Programa de Pós-Graduação em Crítica Cultural (UNEB/Campus II). Endereço eletrônico: jailmapedreira@uol.com.br.
} 


\section{Introdução}

No texto que por ora apresentamos a escrita memorialística de autoria feminina foi pensada a partir de Lacerda (2003) que nos ajudou a refletir sobre como esta escrita foi por muito tempo considerada um escrito sem valor, por se tratar de uma literatura que centra a sua construção com base nas experiências vividas pelas escritoras. Teóricos como Klinger (2012), Santiago (2008) e Arfuch (2012) com suas discussões sobre memórias, autobiografia e a escrita de si são também fundamentais para percebemos como a primeira pessoa atravessa a ficção contemporânea, tornando complexos os limites entre o texto real e ficcional. Assim, esta narrativa contemporânea como se apresenta por vezes é entendida pelos estudiosos como uma autoficção. A escrita de si e a escrita do outro se tornam os dois elementos fundamentais desta literatura, o autor imprime a sua marca autobiográfica nas suas produções.

A escrita feminina, neste texto, também foi pensada a partir das discussões traçadas por Nelly Richard (2002, p. 135), pois esta nos diz que é preciso por em relação os textos produzidos por homens e mulheres, "considerando semelhanças e diferenças, reconhecendo conquistas e aportes, mas também limitações" dos textos femininos. Deste modo, não nos interessa saber a verdade de uma possível particularidade dessa escrita produzida por mulheres, mas sim indagamos como as marcas do feminino são textualizadas, como estas se fazem presentes no "corpo vivo", ao mesmo tempo em que nos mostram como esse corpo vivo se apropria de uma escrita, encenando, ou não, uma diferença na dinâmica tensional. Dessa forma buscamos observar como emergem os escritos autobiográficos de mulheres, sob que condições e que diferenças, que reflexões eles provocam, considerando as marcas de exclusão, a ficção contemporânea, e ainda os dispositivos de controle atuais e a possiblidade de repetição, ou não, destes, por um movimento de escrita de mulheres. 


\section{Autobiografia: lugar de vozes femininas, de singularidades}

No texto Álbum de família: memórias de vida, histórias de leitoras (2003), a autora Lilian Lacerda destaca o diário, memória e autobiografia como sendo a clássica trilogia da escrita memorialística. E o que vai diferenciar essas escritas, segundo a autora, de outros gêneros literários é o que o autor Philippe Lejeune define de pacto autobiográfico.

Assim, Lilian Lacerda apresenta um panorama do contexto de "produção e socialização" da literatura autobiográfica feminina no Brasil. Uma literatura que centra a sua construção com base nas experiências vividas pelas escritoras, marcada por indicações cronológicas, mas que não se prende a uma linearidade. Essa literatura autobiográfica, de uma perspectiva internacional, ganha visibilidade em determinado momento, como nos diz Lacerda:

Pensando retrospectivamente, é no contexto dos anos 1960 que as escritas autobiográficas ganham evidência, ou seja, é nesse período que o mercado editorial em vários países do mundo passa a publicar registros pessoais de grupo minoritário (ao menos do ponto de vista de prestígio social), como negros, mulheres, homossexuais, prisioneiros, camponeses e outros (LACERDA, 2003, p. 40).

Segundo Lacerda (2003, p. 73), a literatura do tipo memorialístico só foi reconhecida no Brasil recentemente, pois no final dos anos 80, essa modalidade de escrita ainda era desconhecida pelos estudos da historiografia da mulher, pela literatura brasileira e pelos estudos memorialistas, ganhando credibilidade em 1991, quando foi localizada e analisada uma produção da literatura de tipo autobiográfico. Essa literatura memorialística ecoa como uma resposta ao silenciamento que os grupos minoritários sofreram no período ditatorial, e muitos desses textos autobiográficos foram produzidos por mulheres de diferentes classes sociais. Tal literatura tem sido cada vez mais estudada, visto que a mesma tem posto em xeque um contorno do literário. Como explica Lacerda:

o traço literário, por vezes, dá ao texto características ficcionais e, por isso, poder-se-ia levantar suspeitas sobre o que é ou não verossímil na escritura. Essa questão é cada 
vez mais debatida no campo da Teoria Literária e nos estudos sobre o memorialismo: realidade e imaginação, vivência e representação (LACERDA, 2003, p. 39-40).

Além desta marca importante a se considerar nesta escrita ao rastrear a produção e publicação das escritoras brasileiras memorialistas, Lacerda (2003) percebe que existe um hiato que separa esses dois momentos da escrita literária de autoria feminina, pois existem períodos grandes entre uma etapa, da produção, e outra, da publicação.

É importante destacar que embora mulheres escrevam há bastante tempo, a entrada destas no cenário literário só ocorre timidamente por volta do século XIX, provocando mudança de ordem socioeconômica, política e cultural. As mulheres destinadas a ser consumidoras dessa literatura, passam também a produzi-la, mas o acesso a condição de produtoras textuais não lhes foi facilitado.

Por certo, além de haver a predominância da escrita masculina, os vários textos que faziam referências às mulheres também eram escritos por homens. Desta forma, a sociedade atestava uma "inferioridade mental, moral e física do gênero feminino" (DUARTE, 2011, p. 234). Mas o que se podia observar era que os homens não eram os detentores dos talentos da escrita, mas sim dos meios para desenvolvê-la, como nos diz Constância Duarte (2011). Para a autora, muitas escritoras que "ousaram" publicar seus textos os perderam nos arquivos ou estes não passaram da primeira edição.

A escrita de mulheres era muitas vezes grafada em forma de diários, visto que era uma prática utilizada pelas moças desde o século XIX. Tais mulheres dividiam o tempo da escrita com as tarefas domésticas, pois o espaço da escrita feminina muitas das vezes se resumia apenas ao ambiente doméstico.

Esses escritos de caráter intimista foram considerados, por muito tempo, como papéis de valor duvidoso. Uma vez publicados, alimentaram uma rede em formação - a literatura nacional e, particularmente, a literatura de corpo feminino. O hiato entre escrever e editar revela parte das condições sócio-históricas enfrentadas para a edição de seus escritos, dentre eles, os de cunho pessoal 
como são os diários, os romances autobiográficos, os depoimentos, as memórias, algumas crônicas esparsas, os relatos de vida e as autobiografias (LACERDA, s/d, p. 2).

Como vimos tais escritos intimistas produzidos muitos por mulheres não eram considerados, mas hoje podemos observar que há uma crescente multiplicação da escrita de si e que não a encontramos apenas no cenário literário, mas também em outros domínios das artes.

Lacerda (2003) questiona o porquê desta literatura memorialística ganhar visibilidade a partir dos anos 60 e passa, assim, a elencar algumas possibilidades. A preocupação com uma nova historiografia literária que produza novas alternativas para a escrita feminina literária é um argumento ou se configuraria em uma demanda, que apontaria para uma visibilidade a se construir, visto que já se poderia vislumbrar uma revisão da historiografia, abarcando vozes femininas que não foram consagradas pelo cânone.

A escrita feminina de cunho memorialístico, como já dissemos, a partir de Lacerda (2003), ecoa no Brasil com força no período pós-ditadura e sofre influências do mercado editorial europeu que já vinha absorvendo as escritas de cunho autobiográfico das minorias desde os anos 1960. Essa escrita que traz a singularidade de cada sujeito torna-se propícia para aquele momento, como uma possível resposta às repressões políticas sofridas.

O silenciamento da mulher e sua escrita, até este período, diz do sistema sócio-político vivido, de uma "censura ideológica e cultural" (LACERDA, 2003). A mulher e escritora é posta em um segundo plano na sociedade, sendo atribuído a esta um "segundo lugar", um lugar ausente, certamente também por conta da diferença que encena: um outro sujeito escrevendo que não o masculino e a possiblidade de um outro texto com outras marcas.

\section{Ampliando a diferença com e para o feminino}

É com Derrida (2001) que podemos politizar mais esta questão, visto que através da sua noção de différance, que abala as oposições binárias (homem/mulher; presença/ausência etc.), efetuando a "tensão entre o que 
pode ser uma coisa e seu contrário" (ARFUCH, 2012, p. 15), é possível questionar o significante (as representações) e desestabilizar os sentidos. Ao funcionar como um sistema aberto, a diferença cultural, ou melhor, o espaço intervalar entre eu/outro abala a autoridade do signo (do código patriarcal, por exemplo), fazendo emergir as diferenças, as margens, as vozes silenciadas da sociedade.

Desse modo, a escrita canônica passa a ser questionada, inclusive os seus espaços arbitrários, de dominação (instituições literárias, mercado do livro, Academia de Letras etc.). Forçando este movimento são destacados os textos memorialísticos-autobiográficos, escritos por mulheres, num espaço intervalar entre a ficção e a realidade, entre a literatura e o relato pessoal. Textos, portanto, que usam um gênero de escrita até então não muito considerado por um código literário patriarcal. Texto que empodera o "eu" sujeito que agora pode escrever/narrar as suas experiências. Contudo, para que o discurso dominante não se reinscreva ou continue se reinscrevendo nesses textos, torna-se imprescindível questionar tais escritas, buscar para além da diferença a differance. Assim, pensar as relações de gênero implica pensar na desterritorialização dos sentidos fixados, os quais atribuíram aos sujeitos femininos um "segundo lugar". Pensar este jogo de desterritorialização, observando como as escritoras estão se ressignificando e por vezes ainda repetindo uma imagem patriarcal construída para mulheres.

Como bem nos diz Jeffrey Weeks (2000)

\begin{abstract}
O gênero não é uma simples categoria analítica; ele é, como as intelectuais feministas têm crescentemente argumentado, uma relação de poder. Assim, padrões de sexualidade feminina são, inescapavelmente, um produto do poder dos homens para definir o que é necessário e desejável - um poder historicamente enraizado (WEEKS, 2000, p. 43).
\end{abstract}

Nesses termos, o feminino é construído em meio a relações de poder, a "escrita de si" emerge nos estudos literários como um "texto vivo", que traz diversos significados tanto da subjetividade do "ser vivente" (AGAMBEN, 2009), quanto de outras assimiladas, impostas, negociadas no processo intersubjetivo. Esses textos memorialísticos, que narram escritas de si, trazem as marcas de 
vida não só de um "eu”, mas de toda uma coletividade. Uma coletividade marcada, diferentemente, singularmente, por questões de gênero, raça, classe, regionalidade que muitas vezes agem de forma interseccionalizada. Este texto vivo quando emerge, o faz também por conta destas relações de poder e em meio a elas, como já dissemos. Um texto que expõe uma marca e aponta para outras marcas, marca outras possibilidades. Assim, a violência simbólica contra pobres, negros, mulheres não ocorre por acaso. As interdições nas formas de viver do sujeito feminino não são inocentes. Desse modo, os discursos que atuaram nos contextos coloniais, por exemplo, continuam em plena atividade nos tempos atuais. Os modos de controle, diversificados, continuam em cena. Isso requer, inclusive da perspectiva da mediação, de um crítico cultural, cada vez mais: estudar, relacionar, confrontar e construir uma política que afirme a vida em suas diferenças. Uma política que não repita um sentido da diferença que a desvaloriza, que a repete como segundo lugar, como foi feito para o feminino e sua escrita. Uma política que questione as interdições e nos revele os sujeitos, construindo e desconstruindo a si e as suas vidas, em meio a estas relações de poder.

\section{Entre o real e a ficção: escrevivências do "outro"}

O que podemos observar, como nos apontam alguns autores (KLINGER, 2012; SANTIAGO, 2008; ARFUCH, 2012), é que essa primeira pessoa vem atravessando, também, a ficção, complexificando os limites entre o real e o ficcional. $\mathrm{Na}$ atualidade alguns teóricos vêm chamando a atenção para o conceito de autoficção e para o fato de como a primeira pessoa autobiográfica tem transpassado a prosa literária da América Latina. Podemos tomar como exemplo, a pesquisadora Diana Klinger, que em seu texto intitulado Escrita de si como performance (2008), debate como o conceito de autoficção torna-se um conceito específico da narrativa contemporânea. Para a autora, com o fim do "paradigma moderno das letras", a literatura passa a assumir a forma de autoficção.

Em sua outra obra intitulada Escrita de si, escrita do outro: o retorno do autor e a virada etnográfica, a autora Diana Klinger cita a narrativa de três obras latino-americanas que apresentam dois elementos que marcam as 
narrativas contemporâneas, a saber: "a presença marcante da primeira pessoa e um olhar sobre o outro culturalmente afastado" (2012, p. 10). Ou seja, os narradores apresentam na trama marcas autobiográficas, escritas de si, ao mesmo tempo em que, também, escrevem sobre o outro ao "atravessarem uma fronteira cultural". Deste modo, a autora entende que o "retorno do autor" e a "virada etnográfica" se constituam hoje como sendo a marca da narrativa contemporânea.

Ao discorrer sobre a escrita de si a autora dialoga com Ítalo Moriconi para falar dessa presença autobiográfica dos escritores nas narrativas ficcionais, percebendo, assim, que as fronteiras entre o real e o ficcional diluem-se.

A definição que a autora utiliza no seu texto baseia-se nos estudos de Philippe Lejeune (1996) para pensar a diferenciação entre um texto ficcional e um texto autobiográfico, entendendo que a autobiografia não diz da relação dos fatos vividos pelo autor e a forma como este emprega no seu texto escrito, mas sim de um pacto que o autor firma com o seu leitor. Sendo assim, um texto para ser ficcional ou autobiográfico vai depender se "o pacto estabelecido é ficcional ou referencial" (KLINGER, 2012, p. 10).

Diana Klinger vem mostrar como os romances operam uma transgressão, em alguma medida, com o pacto ficcional, pois apresentam elementos que teriam quer ser analisados por outro prisma, o referencial.

O espaço autobiográfico compreende o conjunto de todos
os dados que circulam ao redor da figura do autor: suas
memórias e biografias, seus (auto)retratos e suas
declarações sobre sua própria obra ficcional. Se, num
sentido geral, todo texto de ficção participa do espaço
autobiográfico, as ficções em primeira pessoa e com traços
autobiográficos ocupam aí um lugar de destaque,
estabelecem o que Lejeune chama de "pacto indireto" pois
o autor, por meio de algumas indicações, os dá a ler
indiretamente como "fantasmas reveladores do
individuo" (KLINGER, 2012, p. 10).

Sendo assim, as obras literárias contemporâneas assim como as apresentadas por Klinger não se rendem a uma única categoria - autobiografia 
e romance - mas sim transitam pelos dois espaços. Dessa forma, o que podemos observar na explanação da autora, é que esse conceito [autoficção] abre várias possibilidades de construções narrativas dos textos com um referencial biográfico. Por exemplo, os nomes dos personagens também podem ser o nome dos autores etc. Nesse emaranhado de histórias podemos encontrar autores que irão dizer que suas criações são puramente ficcionais, outros assumirão que utilizam da vida real para criar as histórias e personagens ou veremos que o personagem é o próprio autor.

Para Klinger (2008, p. 13), “A escrita de si é um sintoma da época atual", assim, as experiências dos autores têm servido como pano de fundo para os romances contemporâneos. Vejamos o que a escritora Conceição Evaristo nos diz:

Tem um conto em Insubmissas lágrimas de mulheres que quando eu acabei de escrever eu chorava, então ao mesmo tempo eu fico muito feliz porque eu sinto que eu me dou, é um exercício que me custa, mas é um exercício que é meu mesmo, parto da minha experiência, parto da minha vivência, não que eu tenha vivido, até porque eu precisava ser mil pra viver, por exemplo, alí são 13 personagens, mas é um processo tão introjetado que tem tanto a ver com a minha vivência de uma forma ou de outra. Talvez por isso eu posso dizer a nossa escrevivência (EVARISTO, 2012) ${ }^{3}$.

O conceito escrevivência, utilizado pela escritora, diz de uma escrita que parte das experiências vividas pelo autor durante o percurso da sua vida. Conceição Evaristo ainda nos afirma que a base da sua escrita está relacionada com as experiências de oralidade que viveu no núcleo familiar, o primórdio da sua literatura está na convivência com os pais, na contação de histórias, sendo essas histórias inventadas (ficções) ou histórias do dia-a-dia, mas todas viravam depois um caso a ser narrado. Podemos dizer que escritas como a de Conceição Evaristo tornam híbridas as fronteiras entre o real e o ficcional. $\mathrm{Na}$ verdade, a fala, supracitada, de Evaristo, confirma que "o texto autobiográfico constitui-se, então, como um gênero com fins literários mais definidos, com

\footnotetext{
${ }^{3}$ Informações concedidas pela escritora no encontro realizado, em março de 2012, na UNEB Campus II, durante evento intitulado, "Roda de conversa: Conceição Evaristo e Escritoras de Alagoinhas e Região".
} 
forte apelo à narração em detrimento à descrição e, além disso, o estilo é mais pessoal e auto-referencial" (LACERDA, 2003, p. 40-41).

A abordagem autobiográfica tende a possibilitar o entrelace das histórias individuais com as histórias sociais, pois a singularidade e o coletivo pluralizam os discursos e, por sua vez, o modo de pensar e atuar dos sujeitos na sociedade. Ao escreverem sobre suas lembranças, seu cotidiano, trazem os rastros das desigualdades sociais, das marcas de violências nos corpos, dos discursos sobre a sexualidade, dentre outros. Assim, por em relação os discursos que perpassam nos textos dos escritores, no nosso caso das escritoras, nos permite não só visualizar as trajetórias pessoais, mas o outro (marcas discursivas) que se expressa nessas escritas.

A segunda marca, dessa narrativa contemporânea, então seria a escrita do outro, ou seja, "a virada etnográfica” apresentada por Klinger (2012) através de uma literatura "pós-boom" e "pós-ditaduras" em que os autores têm se debruçado sobre os sujeitos [figuras] marginalizados da sociedade.

\begin{abstract}
A "atração pelos sujeitos marginais" e o "dilema da representação da outridade" são também, como mostra Hal Foster, problemáticas das artes contemporâneas. Foster propõe a existência, no final do século, de um paradigma do "artista como etnógrafo", semelhante ao paradigma do Benjamin do autor como produtor. No entanto a virada etnográfica excede o campo das artes: ela implica também uma "transfronteirização" do conhecimento a partir da problemática da cultura. Com a ampla difusão dos estudos culturais, as fronteiras entre disciplinas humanísticas foram se enfraquecendo, de maneira que, [...] aconteceu uma "antropologização" do campo intelectual (KLINGER, 2012, p. 12).
\end{abstract}

Para Diana Klinger (2012, p. 60) no capítulo A escrita do outro - a virada etnográfica, na atualidade existe uma "problemática central" que atravessa a arte assim como a literatura, que seria o paradoxo "de uma linguagem situada entre uma hermenêutica do outro e a tautologia de si". A "outridade" apresenta-se de forma incisiva nessa narrativa contemporânea. Assim, Klinger apresenta os argumentos de Resende ao falar sobre essa “outridade" na literatura nacional dos anos 1990. Esta acredita que a presença 
do socialmente excluído tem uma expressividade preponderante e que vai perdurar por bastante tempo. Essa exclusão tende a abranger tantos outros como as mulheres, negros, índios etc. Diferentemente de outrora, o socialmente excluído surge na literatura como uma "alteridade a ser reivindicada".

Klinger (2012) retoma Foster que, ao dialogar com Franco Rella, demarcam que teóricos como Lacan, Foucault, Deleuze e Guattari tem uma visão romântica do "outro", visto que estes teóricos idealizam o "outro". Para Foster esta idealização apenas privilegia um grupo socialmente excluído e que logo será substituído por um outro, sendo este um posicionamento político que tende a consumir o outro.

Klinger (2012, p. 65) então se posiciona afirmando que o que estamos vendo na atualidade "é a reformulação da categoria do 'outro". Pois, este sujeito socialmente excluído está falando e escrevendo por ele mesmo. Diferentemente do que propôs Foster, Klinger percebe que existe um apagamento e não o retorno da "fantasia primitivista" do outro.

Assim, “a construção da figura do 'outro' vinculada à presença marcante da primeira pessoa desconfia da transparência e da neutralidade, e, assim, questiona a ideia de representação"(KLINGER, 2012, p. 12). Klinger nos convida a pensar a crise da representação a partir das contribuições de Derrida. Assim, esta pondera:

Derrida formula a desconstrução da noção de representação a partir da noção de envio (Geschick). Um envio não constitui uma unidade, e não tem nada que o preceda. Não emite senão remete: "Tudo começa no remeter, ou seja, não começa". Essas pegadas, esses rastros, são remissões a um passado sem origem do sentido, remissões que não têm estrutura de representantes nem de representações, de significantes, nem de signos, nem de metáforas etc. As remissões do outro ao outro, as pegadas de différance, não são condições originárias e transcendentais. São um envio, um destino (Geschick) que "não está nunca seguro de se juntar, de se identificar, de se determinar" (KLINGER, 2012, p. 44). 
O que podemos observar também a partir de Klinger (2012, p. 13) é que a Antropologia contemporânea com a virada etnográfica, que tem transversalizado as artes, mas, também o campo intelectual humanístico, vem questionando essa representação, ou seja, vem tecendo críticas em relação à representação a partir do momento em que os estudiosos voltam o seu olhar para si, visto que abandonando a "pretensão de objetividade e de neutralidade científica, os textos da antropologia pós-moderna narram experiências subjetivas de choque cultural".

\section{A escrita de si "feminina": texto vivo em meio a dinâmica tensional}

Partindo da problemática da representação, podemos pensar sobre as diferenças existentes entre a "escrita de si" de escritores e escritoras, seus traços memorialísticos. Suas ficções e relatos autobiográficos nos mostram que não há uma forma discursiva fixa que particulariza essas narrativas, mas uma pluralidade de modos de dizer sobre o "eu" e "outro", compartilhados de um contexto histórico, social e econômico. Se pusermos em diálogo essas escritas podemos perceber as proximidades e diferenças entre a escrita feminina e masculina, a multiplicidade dos modos de dizer sobre si mesmo e o outro, o que nos leva a debater sobre as marcas de gênero na escrita. "A partir dos estudos culturais e dos estudos de gênero, a crítica cada vez mais tende a refletir sobre o próprio sujeito da escrita" (KLINGER, 2012, p. 13).

Neste sentido, não podemos deixar de falar acerca do lugar do sujeito feminino, do seu modo de dizer posicionado que, nem sempre, é expresso pelo outro, e que traz as marcas construídas, sentidas, ressignificadas do corpo feminino. Trata-se de um modo de dizer múltiplo, mas que se singulariza a partir do lugar que esse sujeito ocupa, das relações de forças que se estabelecem e do modo como as subjetividades vão sendo tecidas diante das interdições e enfrentamentos patriarcais.

De modo geral, os homens tiveram as oportunidades que faltaram às mulheres, conheceram outras literaturas, outros lugares, outros modos de dizer; a escrita destes estará impregnada com esses lugares, rostos, cheiros, 
sabores etc. que apreciaram. As mulheres, pensando de um modo geral e histórico, não tiveram a mesma vivência que os homens, visto que certas mulheres foram educadas somente para se tornarem mães e donas de casa. Geralmente, na escrita dessas mulheres, essas marcas sociais, culturais, em alguma medida emergem intervindo na sua construção literária. As mulheres, pensando ainda em um plano histórico e de maioria, não foram educadas para escrever, ou seja, não tiveram as mesmas oportunidades que os homens, por isso é preciso construir condições para que as mulheres se apropriem das várias formas de dizer.

Porém, não podemos deixar de perceber que a escrita de voz feminina autobiográfica ganha à cena na atualidade, abalando os obstáculos impostos que são enfrentados pelas mulheres no exercício da escrita, desativando os processos de silenciamento prescritos por um pensamento hegemônico que determinava a forma de ser e de viver do sujeito feminino. Estas formas, ou marcas culturais, como já dissemos, nos interessa como denotação de um tempo que, com diferença, pode ainda se repetir.

Nelly Richard (2002, p. 131), no texto “A escrita tem sexo?", questiona a crítica em relação à especificidade e a diferença do "feminino", no sentido de ampliar o debate acerca da "marca de sexo e de gênero na escrita". Afirma a autora que a neutralidade do discurso que aposta que não há diferenças entre a escrita e a linguagem genérico-sexual, “equivale a reforçar o poder estabelecido, cujas técnicas consistem, precisamente, em levar a masculinidade hegemônica a se valer do neutro, do im-pessoal, para falar em nome do universal".

Em primeiro plano, a crítica literária feminista passou a evidenciar a autoridade abusiva que exigia que as mulheres escrevessem de acordo com as regras de universalidade, por conseguinte, estimulou "modelos afirmativos e valorativos do ser mulher", no sentido de criar um "sistema de referências autonomamente feminino". Porém, esse separatismo, que acredita na relevância de um saber independente, não percebe que priva "o feminino de uma comunicação plural e dialógica com as múltiplas redes de cultura, nas quais se inscrevem os signos homem e mulher" (RICHARD, 2002, p. 132). 
Com isso, a autora mostra que a escrita naturalizada masculina (universal), operada à força arbitrária, tornou-se a representação do gênero humano, e que, por sua vez, também deve ser combatida tendo em vista o que ela carrega de mais reacionário, violento e opressivo. A autora sinaliza que "ser mulher" não garante a prática crítica de uma feminilidade, que questiona a masculinidade hegemônica, inclusive "ser homem" não condena o sujeito a ser seguidor das “codificações de poder da cultura oficial” (RICHARD, 2002, p. 135).

Segundo Soledad Bianchi (apud RICHARD, 2002, p. 135): “É necessário romper o gueto do sexo, pois se trata de situá-los (os textos de mulheres) junto aos outros, produzidos por homens e mulheres contemporâneos, considerando semelhanças e diferenças, reconhecendo conquistas e aportes, mas também limitações".

Essa crítica evidencia que é preciso reconhecer também os limites dos textos das mulheres, para evitar certas armadilhas do signo e manutenção do discurso oficial de unificação do texto através de certos reducionismos e determinismos. Assim, a crítica é obrigada a pensar o "feminino em tensão com o marco da intertextualidade cultural e não como uma dimensão a ser isolada". Acrescenta ainda a autora que:

\begin{abstract}
As mulheres não podem se dar ao luxo de não participar ativamente dessas batalhas [múltiplas batalhas de código], mesmo que as regras do combate estejam prefixadas a partir do masculino, já que em toda cultura há entrelinhas rebeldes, por onde filtrar e disseminar os significados antipatriarcais. É vital resgatar, a favor do feminino, todas aquelas vozes descanonizantes (incluindo as masculinas) que liberam leituras heterodoxas, capazes de subverter e pluralizar o cânone. Esses pactos, cúmplices entre distintas posições de discursos marcados pela subalternidade cultural, ampliam o poder do feminino, naquilo que Jean Franco chamou de "a luta pelo poder do interpretativo" (RICHARD, 2002, p. 157).
\end{abstract}

Mostra-nos Richard (2002, p. 137) que não se trata de saber a particularidade da escrita da mulher, mas "como textualizar as marcas do feminino, para que a diferença genérico-sexual se torne ativo princípio de identificação simbólico cultural". Assim, ela evidencia as conquistas da crítica 
feminista em relação ao caráter semiótico-discursivo da realidade e demonstra que a identidade e gênero sexuais são produzidos pelo discurso patriarcal.

Portanto, "não podemos continuar falando de uma identidade, masculina ou feminina, como se estes termos designassem algo fixo e invariável, e não constelações flutuantes" (RICHARD, 2002, 138). Desse modo, trata-se de por em questão os essencialismos, repensar a identidade sexual como uma dinâmica tensional e buscar romper, desconstruir os resquícios ideológicos dos discursos autoritários, patriarcais que subjugam a mulher.

Apropriamo-nos da fala de Louro (2000) quando esta nos diz:

\begin{abstract}
Na verdade, desde os anos sessenta, o debate sobre as identidades e as práticas sexuais e de gênero vem se tornando cada vez mais acalorado, especialmente provocado pelo movimento feminista, pelos movimentos de gays e de lésbicas e sustentado, também, por todos aqueles e aquelas que se sentem ameaçados por essas manifestações. Novas identidades sociais tornaram-se visíveis, provocando, em seu processo de afirmação e diferenciação, novas divisões sociais e o nascimento do que passou a ser conhecido como "política de identidades" (LOURO, 2000, p. 7).
\end{abstract}

É importante ressaltar que o modo como se constrói a narrativa pode revelar os dispositivos que lhe impedem de ter acesso a outras possibilidades de luta com e contra o signo. A ausência do direito à educação, o discurso paterno, a escrita oficial, a literariedade, a dificuldade para publicar, a não circulação dos seus textos, dentre tantas interdições revelam que os dispositivos ainda continuam impondo limitações à "batalha" com e contra o código.

Com base em Agamben (2009, p. 40), o qual amplia a noção de dispositivos de Michael Foucault, os dispositivos podem ser "qualquer coisa que tenha, de algum modo, a capacidade de capturar, orientar, determinar, interpretar, modelar, controlar e assegurar os gestos, condutas, as opiniões e os discursos dos seres viventes". Portanto, a vida humana pode estar sendo capturada por qualquer coisa: a literatura, as redes sociais, a caneta, o 
computador, celular etc. Então, como desarmar esses dispositivos que controlam o nosso modo de dizer e ler o mundo e nossas experiências?

A "escrita de si" dos escritores contemporâneos mostra o quanto é carregada de sentidos e fala de uma coletividade. A "escrita de si" feminina é repleta de singularizações, pois traz a marca da "diferença cultural", a forma de viver dos corpos femininos que, em geral, não são narrados por outros sujeitos, traduzindo-se em uma arma política que tensiona as questões de gênero.

\section{Considerações finais}

Assim, o que podemos dizer é que esta escrita memorialística feminina, que foi, por muito tempo, subjugada, desprezada, por se tratar da escrita em primeira pessoa, uma escrita que por ser produzida por mulheres não merecia ter atenção, ser prestigiada, uma escrita produzida a partir da vivência da sua autora, esses mesmos escritos tem se constituído como uma forma de rompimento do silenciamento destas mulheres. Esta escrita de si, uma outra representatividade, tem contribuído para uma guinada na subjetividade das mulheres, que tomam a palavra para si, assim também a direção das suas vidas, das suas histórias de lutas, escrita que empodera os sujeitos femininos em um processo de fortalecimento dos mesmos.

Se esta literatura memorialística ecoou no Brasil como uma resposta ao silenciamento ao qual as minorias eram submetidas, essa literatura, essa escrita de si continua contribuindo para o desativamento dessas marcas que os sujeitos carregam em seus corpos. Uma escrita literária contemporânea que "trai" o pacto autobiográfico, pois se abre para novas perspectivas, novas formas de operar com o texto literário e com o texto-vida.

\section{Referências}

AGAMBEN, Giorgio. O que é um dispositivo? In: $O$ que é o contemporâneo e outros ensaios. Trad. Vinicius N. Honesko. Chapecó: Argos, 2009. 
ARFUCH, Leonor. Antibiografias? Novas experiências nos limites. In: MARTINS, Anderson Bastos; SOUZA, Eneida Maria; TOLENTINO, Eliana da Conceição (Org.). O futuro do presente: arquivo, gênero e discurso. Belo Horizonte: UFMG, 2012.

DELORY-MOMBERGER, Christine. Biografia e educação: figuras do individuoprojeto. Trad. Maria da Conceição Passegi, João Gomes da Silva Neto, Luis Passegi. São Paulo: Paulus, 2006.

DERRIDA, Jacques. Semiologia e gramatologia - Entrevista a Julia Kristeva. In: Posições. Belo Horizonte: Autêntica, 2001, p. 23-43.

DUARTE, Constância Lima. Arquivos de mulheres e mulheres anarquivadas. História de uma história mal contada. In: SOUZA, Eneida Maria de; MIRANDA, Wander Melo (Org.). Crítica e Coleção. Belo Horizonte: UFMG, 2011.

KLINGER, Diana. Escrita de si como performance : Revista da Associação Brasileira de Literatura Comparada [ABRALIC], v. 25, n. 12, p. 11-30, 2008. Disponível em: http://www.abralic.org.br/revista/2008/12/25/download. Acesso em: 12 dez. 2013.

KLINGER, Diana. Escrita de si, escritas do outro: o retorno do autor e a virada etnografica. Rio de Janeiro: 7 Letras, 2012.

LACERDA, Lilian de. Álbum de leitura: memórias de vida, histórias de leitoras. São Paulo: UNESP, 2003.

LACERDA, Lilian Maria de. Edições (auto)biográficas: uma produção de voz feminina. Disponível em: www.intercom.org.br/papers/xxiiici/gt04.gt04a6.pdf. Acesso em: 12 dez. 2013.

LOURO, Guacira Lopes (Org.). O corpo educado: pedagogias da sexualidade. Belo Horizonte: Autêntica, 2000.

RICHARD, Nelly. A escrita tem sexo? In: Intervenções crítica: Arte, cultura, gênero e política. Trad. Romulo Monte Alto. Belo Horizonte: UFMG, 2002, p. 127141.

SANTIAGO, Silviano. Meditação sobre o ofício de criar. Revista Aletria, Editora UFF, v. 18, n. 1, 2008, p. 173-179. Disponível em: $<\mathrm{http}$ ///www. periodicos.letras.ufmg.br/index.php/aletria/article/view/1450/ 1546 >. Acesso em: 05 set. 2014. 
WEEKS, Jeffrey. O corpo e a sexualidade. In: LOURO, Guacira Lopes (Org.). $O$ corpo educado: pedagogias da sexualidade. Belo Horizonte: Autêntica, 2000, p. 37-82.

Recebido em 12 de agosto de 2016

Aceito em 25 de agosto de 2016 